\title{
Public Involvement in Marine Management? An Evaluation of Marine Citizenship in the UK
}

Emma McKinley and Stephen Fletcher, School of Conservation Sciences, Bournemouth University, Fern Barrow, Poole, BH12 5BB, Dorset, UK.

\begin{abstract}
Traditionally, governance of the marine ${ }^{1}$ environment has been a state driven, topdown approach. Recently, however, management has been in a transitional period, moving towards a more participatory, bottom up regime. Future management of the marine environment must take the ever increasing, diverse range of factors effecting the marine environment into consideration (Skourtas et al, 2005). The role of a flexible, adaptive approach allowing for changing social values, environmental requirements and sustainable development has already been recognised (Defra, 2006). Further to this, is the increasing acknowledgement of community involvement in management of UK marine resources (Defra, 2006). The founding rationale of this study is the suggestion that with a greater level of public involvement and responsibility, marine management could be developed at a more sustainable, longterm level. It is proposed that it will ensure successful management and protection of valuable marine and coastal ecosystems and resources, whilst prompting economic and social development and stability. Despite widespread recognition of the role of communities in marine management, currently there are no guidelines regarding promotion of public involvement. This research highlights the recognition amongst marine practitioners that higher levels of citizen involvement in the management of the marine environment would greatly benefit the marine environment, with additional benefits possible through an increased sense of marine citizenship.
\end{abstract}

\section{KEYWORDS: Marine Citizenship, environmental education, responsibility, marine management, public engagement.}

\section{Introduction}

The conservation and management of the marine environment has experienced a transition over the past 40 years, from top down, state directed regimes towards a more participatory, community-based governance framework (Applestrand, 2002; Edwards et al, 1997; McFadden, 2008). This is a trend that has been further promoted in the UK by the Marine and Coastal Access Act (2009), which recommends a participatory approach to the development of marine management and planning. Efficient governance structures involved in managing marine space are vital to marine environments, which are of global importance in terms of their living and non-living resources, ecosystem services and strategic value. However, marine environments are under exceptional pressure as approximately $50 \%$ of the industrialised world's population lives within $50 \mathrm{~km}$ of the coast (Boersma and Parrish, 1999). Given this, the associated industrialisation and urbanisation of the coast has resulted in unprecedented pressure on the marine environment (Ducrotoy et al, 2000; Juda, 1999; Smith, 2001) and the related degradation of the marine environment has been partially attributed to cumulative impacts of day-to-day behavioural and lifestyle choices made by individuals. The role of individuals in marine conservation is therefore increasingly appreciated as being potentially important. Yet whilst literature suggests that both societal participation and education are 'vital' to improved marine governance [Ducrotoy et al, 2000; Kuijper,

\footnotetext{
${ }^{1}$ For this research, 'marine' encompasses coastal, inter-tidal and the undersea environments of the UK
} 
2003; Osborn and Datta, 2006; Jędrzejczak, 2004), relatively little research has been conducted on how the everyday behaviour of the wider public could be engaged to support marine conservation and management in the UK.

The rationale underlying this study is the proposition of a form of marine governance, engaging individuals as policy actors through altered behaviour and lifestyle choices to reduce negative human impacts on the marine environment. Current methods of protecting the marine environment are largely governmental. Whilst they may involve the public, they do not generally conceive public behaviour as having a role in efficient management strategies. Increased public responsibility would result in inherently more sustainable planning than many centrally driven formulations of marine policy through recognition of the public as key actors in the development and implementation of marine policy. The adoption of citizenship to the benefit of the environment presents a new governmental approach to environmental management, a phenomenon described by Valencia Saiz (2005) as the 'turn' to citizenship as a policy delivery mechanism.

This paper proposes marine citizenship as a potential mechanism to enhance public involvement in marine policy development and implementation, resulting in successful management and protection of the marine environment. Marine citizenship has its foundation in conventional notions of citizenship which emphasise that all citizens should contribute to the achievement of collective social, economic and environmental goals (Fletcher and Potts, 2007; Purcell, 2003: Correia, 2002). Recently, 'citizenship' has been expanded to include environmental behaviour and attitudes expected from members of society, primarily as a mechanism to encourage altered citizen behaviour to reduce environmental impacts. In order to explore the potential role of marine citizenship in marine governance and policy delivery in the UK, a study was conducted to evaluate UK marine practitioner views of both the present and potential future roles of the public in marine and coastal governance and the potential role that enhanced public marine citizenship could play. The paper now continues with a review of the method used to conduct the research, followed by an explanation and discussion of the results.

\section{Method}

Data was collected through a telephone interview survey of marine practitioners in the UK. Telephone interviews were chosen as they overcame potential challenges associated with the widespread geographical distribution of marine practitioners, while facilitating detailed investigation. A total of 42 telephone interviews, each with a duration of 25-80 minutes, were conducted between October 2008 and January 2009. The interviewee profile was designed to achieve representation from a broad range of marine sectors and organisational types. All interviews were transcribed and returned to interviewees to ensure their accuracy. Data analysis was based on a process of data reduction and interpretation as discussed in Creswell (1994).

\section{Results}

This section presents the results of the marine citizenship telephone survey of marine practitioners in the UK. The results are presented thematically with respect to: 1) practitioner attitude to marine citizenship; 2) factors considered important in the development of marine citizenship such as perceived levels of public concern, awareness and sense of responsibility towards the marine environment; and 3) the implications arising from marine citizenship for marine management. Direct quotes from interviewees are included in order to illustrate the observations made through comparative analysis of the data. 


\subsection{Practitioner attitude towards marine citizenship}

The majority of individuals interviewed agreed that the public should play a very active role in marine decision-making. The general consensus suggested that early engagement is the key to encouraging active involvement from the general public in marine governance. It was recognised that there is a moral and ethical obligation on marine practitioners to encourage public involvement as it is "part of the democratic process". In parallel, it was suggested that there was also an onus on individuals to participate in marine governance processes the outcome of which could affect them. However, there was less consensus regarding the level of involvement required to deliver active and meaningful public participation, with one interviewee stating that "everyone has their part to play, but how much?". A minority of participants asserted that the public did not have a useful role in marine governance, with one stating that they were "not entirely convinced by the argument that the general public are stakeholders...[the] contribution they make is often arbitrary". Interviewees also recognised that the role an individual plays can be dependent on a number of factors, including, the "nature of the individual", "locality", both globally and "within the UK", the "individual's knowledge" and "opportunities to be involved".

A number of interviewees identified potential limitations to the development of marine citizenship as either a policy-making or delivery mechanism. For example, one interviewee commented that they "suspect that the general public are very disconnected from the marine environment and as a result the terminology won't work". Other interviewees chose to discuss the meaning and character of citizenship as "a wider understanding, appreciation and acceptance that the sea has an environmental, social and economic function'”'. The general feeling of the interviewees is summarised well by one interviewee who commented that "a feeling of ownership and responsibility for the maritime environment is fundamentally important in ensuring we can achieve sustainable management", indirectly proposing potential elements of marine citizenship. In summary, interviewees were generally supportive of the participatory role of the public in the development of marine policy, but were less convinced of the role of citizens in its delivery.

\subsection{Proposed factors for the development of marine citizenship}

Throughout the interviews, two key themes emerged as factors perceived as important in the development of marine citizenship in the UK. These themes were marine education and personal attachment to the marine environment.

\subsubsection{Marine education}

Interviewees considered that an increase in marine specific education and information availability would encourage higher levels of awareness and concern about the marine environment, ultimately generating societal marine citizenship. This is illustrated by one interviewee who stated that "a high level of environmental education will encourage a greater sense of citizenship". Numerous methods to encourage marine education were mentioned, including greater inclusion in formal school based education and expanded informal learning opportunities (such as in visitor centres, interpretation, etc.) with marine-focused television programmes highlighted as "the best way to target a wide variety of people" and "the number one method" of improving marine education.

Inclusion of marine and coastal issues in the national curriculum was identified as a particularly important avenue for increasing awareness amongst children and their 
parents. Interviewees recognised that "kids teach their parents and make them act" and stated that "schools are the ideal way as kids are the next generation". However, this mechanism has the limitation that "there will be a time lapse before it filters into older society". When considering the impacts an increase in marinefocused education and information availability may provide, it was suggested by one interviewee in particular that this might not alter societal behaviour in any meaningful way. Instead it may engender a "blame culture", which could detract from the aspiration of greater community involvement in marine management.

\subsubsection{Personal attachment to the Marine Environment}

Personal attachment to the marine environment was considered by interviewees to be a key factor in generating a sense of marine citizenship among UK citizens. Personal attachment was interpreted in a variety of ways but included "historical connections", "memories and family connections", and "holidays and recreation". Proximity to the coast was frequently considered to have the potential to affect marine citizenship with interviewees "[expecting] coastal communities [to be] more connected to the marine and coastal environments [than inland communities] and [to] have a higher sense of marine citizenship". Attachment in the form of financial dependency was identified as another important and potential influencing factor for marine citizenship. It was proposed by interviewees that those with higher levels of dependency on the marine environment should theoretically exhibit greater marine citizenship. For example, one interviewee stated that "fishermen are using a renewable resource and therefore should theoretically be the main promoters of marine citizenship since their economic stability it based on the condition of the sea". The concept of personal attachment to the marine environment was found to be socially complex, given the existence of "social differences in perception" towards the marine environment. This statement suggested that perception can be variable although the cultural affiliation with the marine environment in the UK related to the "historical implications of the UK being an island nation" should be expected to have an influence.

Although there was recognition amongst interviewees that there are "impacts of the marine environmental issues on daily lives; health issues, socio-economics and climate control", it was thought that the public "generally do not think about the relationships between their lifestyles and the environment" stimulating a weak sense of societal responsibility for the marine environment. This public disconnection was linked to poor public awareness of marine issues, with one interviewee saying that they did not "think that a lot of people are aware of the impacts that they have" and another suggesting that "beyond a basic awareness, there is very little understanding of the issue". In order to encourage altered societal behaviour, interviewees recommended making marine issues more relevant and "real for day to day life" identifying "small actions [the public] can take", with another suggesting that mechanisms to "educate and empower people" would heighten a sense of responsibility.

\subsection{Implications of marine citizenship for marine governance}

There appeared to be a discrepancy between how policy and legislation could include citizenship, and how it would then be applied. Firstly it was observed that many of the interviewees expected that increased public involvement would result in an elevated sense of ownership towards the marine environment as "management would be more understood by society at large...the more ownership [by the public] the better". This was linked by other interviewees to an increase in knowledge and awareness regarding the marine environment, with one interviewee stating that 
"generally speaking the greater the number of people involved, the greater the knowledge...sense of ownership and the greater chance of sound marine management plans being formulated, delivered and implemented". Interviewees predicted that increased societal awareness and understanding would encourage a greater demand for political action on marine issues as marine issues would have a "higher profile politically". According to another interviewee, the greater publicity could be linked to an "increased concern and awareness" for the marine environment. It was also predicted that public involvement would result in a reduction in conflict and "objections to plans". Overall it was considered that increased ownership and awareness, would "lead to more sustainable decision making and a decision being made that can actually be delivered and achieved". It was also suggested that a higher level of public engagement could "highlight other issues that had not been considered" promoting more integrated marine governance.

Disadvantages of an increase in public involvement identified by interviewees, included that it could make the process "difficult", "harder to manage and take everyone's interests on board" while having the potential to make the process more time consuming and expensive. There was also acknowledgement that public opinion can be affected by what is perceived as fashionable, which risks decisions being "affected by changes in current trends" rather than representing "a fair method that is resilient to changes in public mood". Such short term marine governance decisions were criticised by interviewees who called for a move towards a "long term approach" to "develop win-wins rather than compromises". The short-term nature of many marine decisions also produces "a legacy that we don't really understand when it comes to the marine environment, along with huge cultural issues that we don't understand.

\section{Discussion}

The results of this study provide three areas for discussion: the lack of consensus over the potential role of marine citizenship in marine management; the identification of focused education and a personal connection to the marine environment as key factors in developing marine citizenship; and that the implications of an enhanced sense of marine citizenship are currently unknown. Each of these themes is discussed in turn within the context of the wider literature and related research findings.

First, from the results of the interview survey, it was clear that marine practitioners in the UK place value on public involvement in marine governance, viewing it as instrumental in delivering successful decision-making for the long-term. This observation is largely in line with the thrust of much of the academic debate over 'participation' in marine and coastal governance. However, there was a lack of understanding amongst practitioners of citizenship and of the potential role to be played by the development of marine citizenship as a mechanism of policy implementation. In addition, there was scepticism over the potential role of marine citizenship due to the perceived limited association felt by individuals to the marine environment, a perceived lack of public understanding about the marine environment (for which there is plenty of supporting evidence in the academic literature, e.g. Williams, 2008) and the extent to which non-experts can be involved in marine governance. Such resistance to utilising marine citizenship as a policy tool is potentially problematic given the progressive adoption of citizenship by governments as a mechanism to harness collective action to assist in the resolution of large scale environmental concerns. It may also serve to place the contrast between the role of individuals in terrestrial and marine environmental enhancement in sharper contrast, which in turn many contribute to the perceived sense of futility many individuals have 
regarding how changes in their personal behaviour can affect the oceans (Fletcher and Potts, 2007).

When asked to consider the factors affecting the development of marine citizenship, UK marine practitioners identified relevant education and personal attachment to the marine environment as critical. Links between environmental education and sustainable management of the marine environment have been highlighted in previous research (Kuijper, 2003; Osborn and Datta, 2006; Williams, 2008), supported by the earlier acknowledged relationship between education and environmental citizenship (Hawthorne and Alabaster, 1999; Berkowitz et al, 2004). These studies and the findings from the interview survey support the proposal that targeted environmental education can provide long-term solutions to environmental issues through altered individual behaviour and community attitude (Uneputty et al, 1998). Research by Castle et al. (2010) and Steel et al. (2005) suggests that a detailed understanding of public-held marine knowledge would allow the development of more effective education methods thereby ultimately facilitating a more successful inclusive management regime closely related to marine citizenship. Similarly, observations in this paper support the view that accurate information and an efficient education process will support awareness and concern towards the marine environment. There is a growing body of evidence that any improvement in the knowledge of individuals about the marine environment, whether related to marine citizenship or not, is likely to increase the likelihood of altered behaviour patterns that benefit the marine environment (Ananda, 2007).

Marine practitioners in this study also considered that a greater sense of marine citizenship would be expected from individuals with a high level of dependency on the marine environment, such as people with livelihoods intrinsically linked to the condition of the marine environment, such as fishing communities. By having greater understanding of how individuals with a dependency on the marine environment perceive their governance role, attempts can be made to increase the capacity for meaningful involvement of the public in management processes. In contrast, the model of environmental citizenship proposed by Hawthorne and Alabaster (1999) does not consider financial dependency on the environment to be particularly significant when predicting environmental attitudes and behaviour. Hawthorne and Alabaster (1999) also suggested a poor correlation between income and environmental concern. Similar sentiments were expressed by some of the interviewees, who predominantly thought that environmental issues are often considered to be a 'middle class' issue, which if correct has implications for the capacity of individuals to overcome financial barriers to improved environmental behaviour.

This movement of environmental issues into a social context necessitates greater public involvement in environmental matters (Applestrand, 2002; Beierle, 1998), yet may also be seen as a challenge to scientific 'answers' to policy obstacles. Finally, as Figure 1 illustrates that the enhancement of factors such as public concern, a sense of personal and societal responsibility and marine related education are integral to engendering a higher public desire to be involved in the management of the marine environment. As implied by UK practitioners the model shows that a holistic and sustainable management plan for the marine environment can only be achieved if there is a concentrated effort to increase the capacity of society to be involved. 


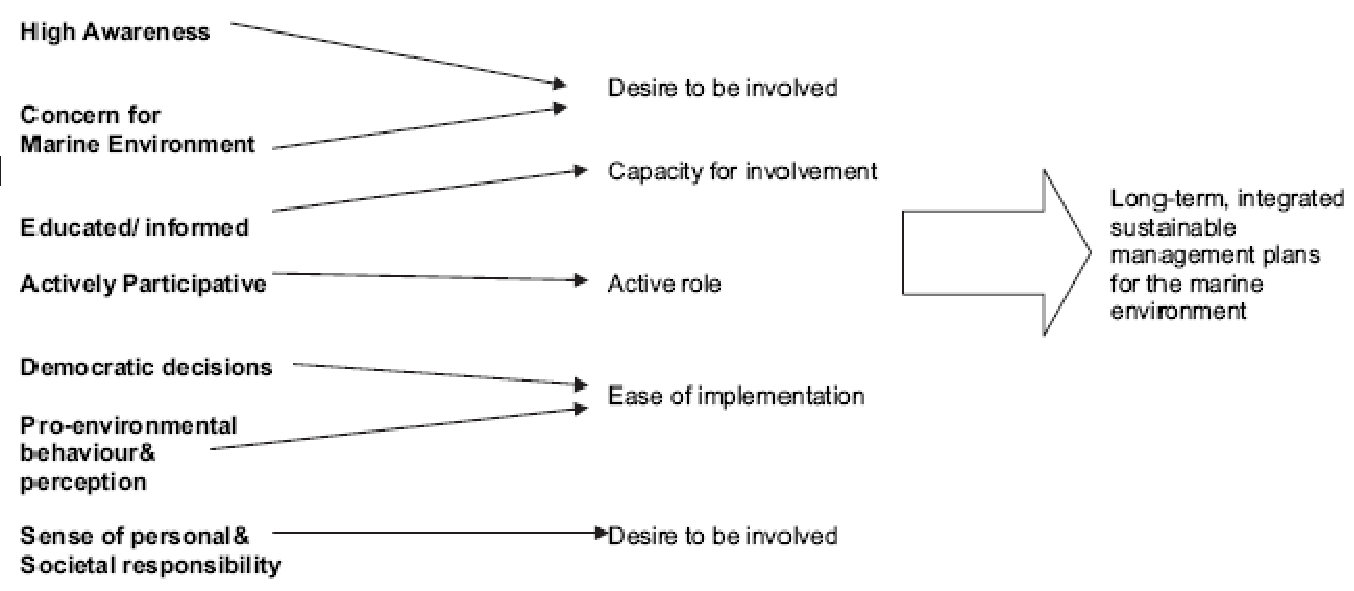

Figure 1: Illustrated model of the influential factors of marine citizenship, their impact on successful management and the eventual outcome following promotion of these elements (Taken from McKinley and Fletcher, 2010).

\section{Conclusion}

This paper presents a detailed investigation into UK marine practitioner perception of the role of the public in marine management. Practitioner perception of the role of the public is important as practitioners often act as gatekeepers to marine governance processes, therefore their attitude towards public engagement and the development of marine citizenship may influence the extent to which it is seen as a credible alternative to centrally driven 'solutions'. The study is timely as there is increasing recognition that governments alone cannot address the pressures facing the marine environment, therefore public involvement in marine governance is likely to come under renewed scrutiny.

From this research, it can be concluded that marine practitioners in the UK consider that the management of the marine environment would benefit from greater citizen involvement, with certain additional implementation benefits available through enhanced marine citizenship. However, there was some scepticism regarding the potential role of marine citizenship, partly related to uncertainty over the concept itself and partly over difficulties in seeing how an effective framework of marine citizenship could be developed. Despite this, support for marine citizenship as a facilitator of policy implementation among interviewees was strong, based on the clear relationship between individual behaviour and the condition of the marine environment. To further the public role, there was evidence (from both this research and the wider literature) that targeted marine education would benefit societal understanding of issues facing the marine environment, subsequently generating a willingness to change behaviour.

\section{References}

Applestrand, M. (2002). "Participation and societal values: the challenge for lawmakers and policy practioners." Forest Policy and Economics 4: 281-290.

Ananda, J. (2007). "Implementing Participatory Decision Making in Forest Planning." Environmental Management 39: 534-544. 
Beierle, T. C. (1998). "Public Participation in Environmental Decisions: An Evaluation Framework Using Social Goals."

Berkowitz, A., R., Ford, M., E., and Brewer, C., A. (2005). A framework for integrating ecological literacy, civics literacy, and environmental citizenship in environmental education. in Environmental Education and Advocacy: Perspectives of Ecology and Education. E. Johnson, A., and Mappin, M.,J. Editors, Cambridge University Press. Cambridge.: 227-266.

Boersma, P., D. and Parrish., J., K. (1999). "Limiting abuse: marine protected areas, a limited solution." Ecological Economics 31: 287-304.

Castle, Z., Fletcher, S., and McKinley, E. (2010). Coastal and marine education in schools: Constraints and opportunities created by the curriculum, schools and teachers in England. Ocean Yearbook. 24: 425-444.

Correia, A. M. R. (2002). Information literacy for an active and effective citizenship: White paper prepared for UNESCO, the U.S. National Commission on Libraries and Information Science, and The National Forum on Information Science. Information Literacy Meeting of Experts. Prague, The Czech Republic.

Creswell, J. W. (1994). Research Design; Qualitative and Quantitative Approaches, Sage Publications, Inc.

De Leeuw, E., D. (1992). Data quality in mail, telephone and face-to-face surveys, Netherlands Organization for Scientific Research: 177.

Ducrotoy, J., Shastri, S., and Williams, P. (2000). "Coastal sciences and management: the need for networking in higher education." Ocean \& Coastal Management 43: 427-444.

Edwards, S. D., Jones, P. J. S. and Nowell, D. A. (1997). "Participation in coastal zone management initiatives: a review and analysis of examples from the UK." Ocean and Coastal Management 36(1-3): 143-165.

Fletcher, S., and J. Potts (2007). "Ocean Citizenship: An Emergent Geographical Concept." Coastal Management 35: 1-14.

Hawthorne, M. and Alabaster, T. (1999) Citizen 2000: Development of a model of Environmental Citizenship. Global Environmental Change 9: 25-43

Jędrzejczak, M., F. (2004). "The modern tourist's perception of the beach: Is the sandy beach a place of conflict between tourism and biodiversity?" Coastline Reports 2 109-119.

Juda, L. (1999). "Considerations in Developing a functional approach to the governance of large marine ecosystems." Ocean Development and International Law 30: $89-125$.

Kuijper, M., W., M. (2003). "Marine and coastal environmental awareness building within the context of UNESCOs activities in Asia and the Pacific." Marine Pollution Bulletin 47: 265-272. 
McFadden, L. (2008) Exploring the challenges of integrated coastal zone management and reflecting on contributions to 'integration' from geographical thought. Geographical Journal 174(4) 299-314

McKinley, E., and Fletcher, S. (2010). "Individual responsibility for the oceans? An evaluation of marine citizenship by UK marine practitioners." Ocean \& Coastal Management 53(7): 379-384.

Osborn, D., and Datta, A (2006). "Institutional and policy cocktails for protecting coastal and marine environments from land-based sources of pollution." Ocean and Coastal Management 49: 579-596.

Purcell, M. (2003). "Citizenship and the right to the global city: Reimagining the Capitalist world order." International Journal of Urban and Regional Research 27(3): 546-590.

Seyfang, G. (2005). "Shopping for Sustainability: Can Sustainable Consumption Promote Ecological Citizenship?" Environmental Politics 14(2): 290-306.

Smith, H, D. (2001) the industrialisation of the world ocean. Ocean and Coastal Zone Management 44 (9-10): 563-566

Steel, B., S., Smith, C., Opsommer, L., Curiel, S., and Warner-Steel, R. (2005). "Public Ocean Literacy in the United States." Ocean and Coastal Management 48: 97-114.

Uneputty, P., Evans. S. M., and Suyoso, E. (1998). "The effectiveness of a community education programme in reducing litter pollution on shores of Ambon Bay (Eastern Indonesia)." Journal of Biological Education 32(2): 143-147.

Valencia Saiz, A. (2005). Globalisation, cosmopolitanism and ecological citizenship. Environmental Politics, Vol. 14, No. 2, pp. 163-178.

Williams, L. Beaufort Research (2008) Public attitudes towards the maritime environment around the Menai Strait and Conwy Bay. CCW Policy Research Report No. 08/16. 55 pages 